\title{
INTERVIEW WITH JOSÉ LAMBERT
}

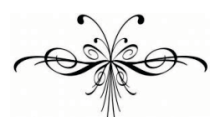

JOSÉ LAMBERT

José Lambert is a professor and scholar in Comparative Literature and Translation Studies, and one of the founders of CETRA - Centre for Translation Studies ${ }^{1}$ - at the University of Leuven, Belgium. Initially, when it was created in 1989, what later became CETRA consisted of a special research program whose purpose was the promotion of high-level research in in Translation Studies, a perennial goal still pursued to this day. Nowadays, José Lambert serves as its honorary chairman. He is also a co-editor of Target - International Journal of Translation Studies ${ }^{2}$ and the author of more than 100 articles. Additionally, he co-edited such volumes as Literature and Translation: New Perspectives in Literary Studies (1978), Translation in the Development of Literatures - Les Traductions dans le développement des Littératures (1993), Translation and Modernization (1995), Translation Studies in Hungary (1996) and Crosscultural and Linguistic Perspectives on European Open and Distance Learning (1998). He has been a guest professor at many universities around the world such as Penn University, New York University, University of Alberta, University of Amsterdam and the Sorbonne, having lectured in many others as well. Starting in 2010/2 he will serve a 2-year tenure as a guest professor at Universidade Federal de Santa Catarina.

The interview here presented is an excerpt of a larger project still in the making and with a broader agenda. In its broader version the project aims at collecting José Lambert's opinions and views on a variety of subjects related to Translation Studies, from its history to its many conceptual and theoretical debates. In this excerpt the focus of the interview is on the history of our discipline as seen from his privileged point of view. Moreover, a few questions make reference to subjects discussed by Gideon Toury in his (recent) article "Incubation, birth and growth: Observations on the first 20 years of Target", published in Target 21:2, and to some assertions brought up in Alice Leal's text "Being a CETRA Student: A Critical Account of the 2009 Summer School", published herein. As a complement to the answers to the questions that refer to the latter text, José Lambert has added a notice that reflects his ulterior reading of that text, which he carried out sometime after he had already answered the questions formulated for this interview.

Gustavo Althoff ${ }^{3}$ and Lilian Fleuri ${ }^{4}$

\footnotetext{
${ }^{1}$ http://www.kuleuven.be/CETRA/index/index.html

${ }^{2}$ http:/ / www.benjamins.com/coi-bin/t_seriesview.coi?series=target

${ }^{3}$ Gustavo Althoff has a major in Social Sciences from Universidade Federal de Santa Catarina (UFSC) and is a PhD candidate at the Postgraduate Translation Studies programme (Pós-Graduação em Estudos da Tradução PGET) in the same institution. He is also the assistant editor of Scientia Traductionis and a researcher at Núcleo de Estudos do Pensamento Político (NEPP) at UFSC. His research interests include the theory and the history of translation, the translation of philosophical texts and its problems, and political theory.

${ }^{4}$ Lilian Fleuri has a major in Portuguese Language and Brazilian Literature, a masters in Translation Studies, and has taught Brazilian Portuguese at Middlebury College (Vermont, USA). She is currently a PhD candidate at the Postgraduate Translation Studies programme (Pós-Graduação em Estudos da Tradução - PGET) at Universidade Federal de Santa Catarina (Brazil). Her focus research area in Translation Studies is Discourse Analysis, Systemic-Functional Linguistics, and Corpus Linguistics.
} 
July, 2010

$\mathrm{S}$ cientia Traductionis: We would like to ask you a little bit about the history of the institution of which you were a founder and has been a member for many years, CETRA. What is the history behind the creation of this centre dedicated exclusively to Translation Studies? What were the difficulties faced in setting it up? And what role has it been playing nowadays as Translation Studies becomes more and more a discipline of global scope and yet of local practice? Does CETRA effectively function as an attracting pole for many different experiences and discussions held at the local level in Translation Studies throughout the world?

José LAMBERT: This is a full program in itself? These are even, I would say, kind questions. I mean, part of the answer is implied. It means that you are convinced that CETRA means something not just for a local institution but for the discipline. Now, I would say that this was the initial ambition. Of course, being afterwards responsible for what we have done I am convinced that we achieved at least part of the goals. But that is maybe promotional talk on my behalf. I would not try to be simply someone who promotes his own initiative. I would like to examine this in a more critical way - so self-criticism is not bad.

There is quite some literature written about CETRA - so it is not for the first time that many people have talked about the initiative, and even big names in the discipline have written about it, like Daniel Gile ${ }^{5}$, Franz Pöchhacker ${ }^{6}$, Andrew Chesterman ${ }^{7}$, etc, and this even happened from the very start. After all, in Leuven, we started CETRA as people who have always belonged to, say, departments of Literary Studies, which was ambiguous because starting up a new discipline within existing departments is, by definition, schizophrenic. And we were in trouble. And by many people we have been identified, even up to this very day, as people who are not really experts in Translation Studies and who are supposed to be linked, rather, with literary translation, and so on.

I can refer to my article that I published in a Portuguese journal called Génesis ${ }^{8}$ in 2005 with the provocative question, the ironical title: "Is Translation Studies too literary?" Now, this was, of course, not about CETRA, not about me, but about the discipline - but of course I was taking it on behalf of myself and of several things. Now, indeed, lots of things that we have tried to develop have been linked, for a certain time, with the question of literature, translated literature; and many people dealing with translation were convinced that, after all, our positions were not really relevant for translation but for particular areas in translation. And in fact this ambiguity - that's what I explain in the article - was also linked with the first

\footnotetext{
${ }^{5}$ http://www.aiic.net/database/datasheet.cfm/int1206.htm \& http:// cirinandgile.com/DGCVEN.htm

${ }^{6}$ http://public.univie.ac.at/index.php?id=14027

${ }^{7}$ http://www.helsinki.fi/ chesterm/

${ }^{8}$ http://www.isag.pt/index.aspx?pag=conteudos | revistagenesis $\mid$ editorial

9 “Is Translation Studies too Literary?”, Génesis. Revista cientifica do ISAI. Tradução e Interpretação, 2005, 5 : 20.
} 
manifestations of the colleagues coming from Tel Aviv and Israel to Leuven - these include Gideon Toury, Itamar Even-Zohar, Zohar Shavit, Rakefet Sheffy (now Rakefet Sela-Sheffy), Nitsa Ben-Ary and Shelly Yahalom (now Shelly Charles). And this initiative is not a matter of people, but it was the real start, first of all, of research on translation at my university and, indeed, on translated literature, but with a larger ambition. But at that moment we were much more narrowly linked with the Department of Literature. Hence the title of our first important and still famous book - Susan Bassnett says this is really the historic symposium on translation: "Literature and Translation: New Perspectives in Literary Studies"10. Now, in that article I tried to show that this title was much too narrow. But of course, after all you are linked with institutional conditions, including even the people that came to us - and there were lots of people who were not at all linked with Literary Studies! The most influential people in that symposium very often happened to have partly literary background but this did not really explain or account for everything that they were suggesting and proposing.

The origin of our ambition with CETRA was to work out something that was developing already in the mid-1970s. But a few people among us were young people and we were all starting intellectuals at the university, and we had no power. We had important meetings at the end of the 1970s and beginning of the 1980s, and the ambition to work out a new forum for research on translation, this ambition was developing because there was a group and there were international contacts. So there was something like networking and we were meeting in different symposia and different disciplines, and we definitely wanted to do something. But then working this out was more difficult because, finally, when you get into action the agreement is not that obvious. The real initiative was taken by Gideon Toury ${ }^{11}$, who, first of all, wanted to start a journal. The second movement, which came a little bit in the continuity of that journal - Target - was that we started to plan this institute - CETRA. This institute was not really planned together by Tel Aviv and Leuven. It was mainly an initiative, say, in Leuven and by several local people, well, locals and friends from international institutions. So the institutional conditions were a little bit better. And the fact that we had already a forum and that we had taken part in publications and so on constituted a stronger basis.

There were also local ambitions and local possibilities that were improving. We got some external finance from a bank in Belgium, CERA Bank - and the name CETRA is still referring to that. So due to some local conditions and due also to the Penn-Leuven Institute ${ }^{12}$, which was a new institute for advanced studies in the area of literary and culture studies, we had the opportunity to integrate translation as a privileged area for high level training of young scholars, say, $\mathrm{PhD}$ scholars, and also beyond. And this Penn-Leuven Institute was very important and gave us the opportunity to start up the training of researchers in translation, and this was new. Now, I can tell that our initiative has been used afterwards, several years

\footnotetext{
${ }^{10}$ http:/ / catalogue.nla.gov.au/Record/2983415

${ }^{11}$ http://www.tau.ac.il/ toury/

12 The Penn-Leuven Institute for Literary and Cultural Studies (1987-1989) was a joint venture between the University of Pennsylvania (nicknamed: Penn) and K.U.Leuven. It consisted of a Summer School entitled "The Penn-Leuven Institute for Literary and Cultural Studies" whose goal was to offer high level sessions organized and provided by prominent international staff to students from (at least) both continents. The Institute does not exist any more (1987-1989). (This information was provided by the interviewee.)
} 
later, by several other institutes. So it has been copied. Now universities try to attract young scholars in Translation Studies and try to provide them with, say, specialized research methodology. I can tell you that whether they say so or not it has been copied from CETRA. So CETRA has been the model for an international training of a new generation of scholars in Translation Studies and the number of people who publish about translation nowadays, the number that has been involved in the training sessions in Leuven is, I would say, in itself, I am very proud about it, impressive! I could give you long lists of names and you can even see them on the website of CETRA; we have about 500 hundred student-researchers or PhDs on five continents.

So we started in 1989 and attracted people from five continents. But we also have a list of top people who have been CETRA Professors and, unfortunately, some among these colleagues have already died; they belong to history. All this means that CETRA is also part of the history of a new discipline. And I am convinced that CETRA as well as our journal - Targethave played a very important role in the establishment of Translation Studies as a new discipline, and even, I would say, in something that you notice locally in Florianópolis ${ }^{13}$. I mean the institutionalization of a $\mathrm{PhD}$ program in Translation Studies which in itself is more than symbolic, and which is absolutely new in the history of universities at the moment when, in fact, disciplines in the Humanities are rather under threat. So I am convinced that CETRA played a role in the international institutionalization of Translation Studies not only because there were new topics and new PhDs - PhDs are important! - but also new profiles and people as well as the organization of scholarly societies, and so on. So I would say this is probably the most important component in my answer.

And what were the goals? Notwithstanding our origins, that is, our literary institutional background, our goals were to establish Translation Studies and not the study of translated literature, and this is made clear in the article in Génesis.

ST: Do you think articles in journals and papers presented in congresses have had a distinguishable weight in helping to constitute Translation Studies as a discipline? What were their roles in the constitution of Translation Studies?

LAMBERT: I would say that these are important and interesting questions. Now, my main answer is very simple. Without claiming to answer on behalf of the full world of Translation Studies, but while being conscious of the fact that I represent a particular approach to this discipline and to its history, I would say my reply is definitively positive. So meetings and the interaction between people studying translation have been very influential - I am not sure if they are as influential now but I know very particular moments where meeting people has been very important, not just because the people involved were picturesque, or interesting, or kind, or wonderful, but because of the things that happened when these people have met.

\footnotetext{
13 The mentioning of Florianópolis refers to Santa Catarina Federal University's Postgraduate Translation Studies programme (PGET): http://www.pget.ufsc.br/?l=en.
} 
Now, the question is more complex. It is concentrating on journals and papers at congresses. Certainly from the contemporary point of view I would distinguish heavily between congresses. So the sociological phenomenon of people meeting during organized meetings congresses, seminars, and so on - that's one thing. Very often papers have been published, not always. Sometimes, some among these meetings were very influential without publishing. But several among these meetings have been influential because the papers have been published and distributed. Now, in our contemporary age, and maybe at the beginning, this was not that clear.

There is also a book market in Translation Studies, and a heavy book market. Now, I do not say that books are not influential but in the use of books, journals and articles by centers, by students, as in Florianópolis, for instance, I would say that I see different options and priorities. And I, myself, am a little bit skeptical about the impact that the contemporary book market has on the discipline. Especially when I go to universities I can see in their libraries (very often little libraries, because, of course, Translation Studies is not a discipline like, say, Historiography) that institutes are heavily dependent on individual books and, say, monographical approaches to Translation Studies. And I would say this is very different from what is first asked here: journals and paper and congresses.

Now, without saying that one is good and the other is bad, I would like to be more concrete and more descriptive in my answer to this question by giving examples of cases that are really of historical importance in the development of the discipline. The first example is the very well known article by James Holmes - I would say it is a classic!: "The Name and Nature of Translation Studies"14. It has been published first as what we used to call at that moment, at the beginning of the 1970s, a "preprint". And it has been published as a preprint in 1972 first and then in 1975. The article has been published again in book form - as one of the more modern approaches to Translation Studies is in book form - in 1988, edited by Raymond van den Broeck, from Antwerp, another very important colleague in the history of Translation Studies at that age (he was already, say, near the end of his career) ${ }^{15}$. But this article, a little by little brushed up, was already known in 1975 and was quoted before, and I am sure that the first version of this article goes back to the 1960s.

Holmes is not a gentleman who published that much and many among his key articles have been used several times. But this article was so programmatic and so central, and it was recognized as such a basic contribution that Holmes himself worked it out and it was really the program of the discipline. Now, just to confirm or to make clear how influential it was I am almost sure that it is on the basis of this article that the name of the discipline, "Translation Studies", has been disseminating. And I would say that a second very important moment in the dissemination of this concept, and even of the influence of this article, but not only this article, is the little book - it was not a big book - by Mary Snell-Hornby ${ }^{16}$ :

\footnotetext{
14 Holmes, James S. (1972/1988). "The Name and Nature of Translation Studies." In: James S. Holmes, Translated! Papers on Literary Translation and Translation Studies, Amsterdam: Rodopi, pp. 67-80.

${ }^{15} \mathrm{http}: / /$ www.benjamins.com/cgi-bin/t_authorview.cgi?author $=24744$

${ }^{16}$ http:/ / transvienna.univie.ac.at/forschung/professuren/dr-mary-snell-hornby/
} 
"Translation Studies: An Integrated Approach"17, published by Benjamins at the end of the 1980s. That is because on behalf of Mary Snell-Hornby, and so on, for the first time, for a real international audience, and with a book that was going to be influential - in this case we talk about a book, not about articles, but she is referring to that article - Translation Studies was in fact integrated into the linguistic approach and even into large circles of translation training. So this article by Holmes, which is used and quoted in all the basic texts by, say, people like Toury - but also by many, many people who nowadays, for instance, would have very different approaches than Toury's - was really used in many meetings.

I would even say that the full career of James Holmes was a confirmation of the importance of the social component in the interaction between scholars in Translation Studies from various fields and from many countries. It must be noted that Holmes was a globetrotter. And one of his secrets, one of the reasons why he was so influential, is that he collected people. He was a great traveler, even in Eastern Europe. He was an American living in Amsterdam, he was a poet, but also a scholar, and a scholar with a very particular status in Amsterdam - I had been working in his institute and I know very well how he was behaving. He brought together people like Itamar Even-Zohar ${ }^{18}$, first, and Even-Zohar then brought Toury into the picture. But Holmes had contacts with the people from Czechoslovakia, and many among them, Russians, Van Den Broeck, who was a very personal friend of Holmes, and etc. So there was something like, I would say, a social phenomenon before there was a real question of publications. The publications came afterwards. And very often the publications did not even come. So I know of lots of documents that have been produced and discussed and that have never really been published. So at the beginning there was maybe even the non-publication of several papers - and after all Holmes himself did not publish that much but was influential and symptomatic.

Now, Toury's paper, for instance, is a very similar example. The first formulation of the idea of norms in Translation Studies, I can locate it very well, was the result of the selection of three proposals by Toury to the organizing committee of the Leuven Conference from $1976^{19}$. Toury produced three proposals and we selected that one on "The Nature and Role of Norms in Literary Translation". This was the first formulation of his article - it is on his website $^{20}$. After all, the full career of Toury and the full development of, say, Descriptive

\footnotetext{
17 Snell-Hornby, Mary (1988/1995). Translation Studies. An Integrated Approach. Amsterdam: Benjamins. More info: http://www.benjamins.com/cgi-bin/t_bookview.cgi?bookid=Z\%2038

18 http://www.tau.ac.il/ itamarez/

19 It was entitled"Conference on Literature and Translation".

${ }^{20}$ http://www.tau.ac.il/ toury/works/GT-Role-Norms.htm. The title of the book chapter available via this link is a little bit different than the original paper: "The Nature and Role of Norms in Translation". It is the chapter n.2 of Toury's influential book "Descriptive Translation Studies and Beyond“, published by John Benjamins in 1995.
} 
Translation Studies (DTS) goes back to that article. So these are really the most programmatic articles that I know in Translation Studies, say, before the 1990s. ${ }^{21}$

Even in the beginning of the European Society for Translation Studies (EST) ${ }^{22}$ in Vienna, in $1992^{23}$, at the International Congress "Translation Studies - An Interdiscipline", the introduction and several discussions held there - Mary Snell-Hornby was the initiator there are very much linked, and narrowly linked, with these texts. I know several other cases. And I know also of conferences with very innovative approaches to translation, and short meetings, and so on, that were not really that influential - which does not mean they were not important. I do not really try to support only my own view, but the most impressive discussions at conferences that I have ever attended were the ones that took place in 1976 at the Leuven Conference, where discussions were held during three, four days between James Holmes, Itamar Even-Zohar, Gideon Toury, Andre Lefevere ${ }^{24}$, Susan Bassnett ${ }^{25}$, say, José Lambert, and a few others. There were also five students of mine among them and there is at least one who is surviving well in Translation Studies, Lieven D`hulst ${ }^{26}$, but there was also Kitty van Leuven and etc - the list of names that probably are indebted to this conference for their careers in Translation Studies, this list is extremely impressive. So what were their roles in the constitution of Translations Studies? Notwithstanding the fact that I am reducing my scope because, well, I am a simple individual being in my career, I think that the very origin of Translation Studies is linked with meetings, seminars and discussions, publications afterwards, and the willingness to develop new movements and networking, international networking even beyond the borderlines between, say, communist and non-communist Europe - and even intercontinental contacts.

So the real origin was meetings and the second thing was publishing - though in the beginning we did not have publishing. When I argue a little bit about these books it is because I felt a little bit disappointed. The international infrastructure for publishing books is so powerful now - even for Translation studies. So what I missed at the beginning was exactly that. I had tapes recorded of all these discussions that I call historic. I was so disappointed at a given moment that I have destroyed them. So it is a real shame about my own career noticing that we had no publishing power. Now this publishing power is available. So something changed.

ST: You mention that Holmes` influence in the field can be attributed to him being a "globetrotter" and that he collected people and so forth. Now, you yourself have been travelling around the globe for a while, having established contacts and attended

\footnotetext{
${ }^{21}$ Also critical in the establishment of DTS was Toury's book "Descriptive Translation Studies and beyond" whose references and 'Table of Contents" can also be found on his website: http://www.tau.ac.il/ toury/works/dts.html

22 http://www.est-translationstudies.org/

${ }^{23}$ http://www.est-translationstudies.org/constitution.html : "At the International Translation Studies Congress 'Translation Studies - An Interdiscipline' in Vienna, the participants agreed on 12 September 1992 to establish an international association to be known as the European Society For Translation Studies - EST."

24 http:/ / www.utexas.edu/faculty/council/1998-1999/memorials/Lefevere/lefevere.html

${ }^{25}$ http://www.contemporarywriters.com/authors/?p=authC2D9C28A1123b1B723mUn17D7D53

${ }^{26}$ http://www.kuleuven.be/cv/u0014681.htm
} 
conferences in many different continents and etc. What can you tell us about your efforts, and the efforts of figures such as Holmes, to establish Translation Studies as a discipline in various parts of the world?

LAMBERT: Well, I would say it is very simple and that this is very obvious. It is like public relations. It is an ambassador's function that is important and influential also in research. Of course, I have tried to do this and I was happy enough to be supported to do this. And of course, I was not the only one. Gideon Toury did the same, but in a different style. Now, the fact that he belongs to a country that has been in very difficult situations and that is even, let`s say this, boycotted by quite a few people, even in the scholarly activities, was not very promotional for him.

Now, I was able to use lots of networks and I am grateful for the openness of my own academic world even though I am very often very severe with universities, including with my own. I have been able to travel and to work abroad and to do this in a very liberal, I would say, spirit. I happened to be lucky also in Comparative Literature because the day I became the secretary of Comparative Literature ${ }^{27}$, that is how I got to Canada (Edmonton, Montreal). I was also invited even by the South African Research Council ${ }^{28}$ - well, Mandela was coming, it was clear. I was involved in distance learning, I was involved in so many European Union projects, and etc. So I have been lucky. But, of course, you have to do it. And sometimes you have to do it though it is a mad world when you are travelling all the time; this is not simple, even for family reasons, and so on. But I am also grateful to my family, to my colleagues not to all of them (laughs). In fact, my university has been a real university and even I have been more in trouble when trying to establish Translation Studies than when trying to do international research. So Translation Studies was an enemy among many colleagues at my university. Notwithstanding this I could do it - of course, you need some support... Also it was full of interesting people from the same generation, new people, new students, young people, etc. I would say the academic career, whatever we may say and think about it, is a wonderful and fascinating world and it is worthwhile.

Now, I would be much more severe with our universities as far as the treatment of translation as an academic issue is concerned. And now I do not mean it in terms of bureaucratic things. But I think the real issue of translation is not really a question of language, and certainly not of literature - this schizophrenic view on translation as belonging to Linguistics or Literary Studies, this is so old fashioned... I am convinced that translation is really at the heart of the matter for "universe-city". The world of knowledge cannot work without the dynamics of translation. And even up to now, in the scholarship about this subject, this has hardly been written down! If universities, first of all, do not develop, in an energetic way, an international communication language - and for me it may be English, it may be other languages - they will not support the world of knowledge. So they will not be worthy of being the leaders of

\footnotetext{
27 Associate Secretary of the Federation Internationale des Langues and Litteratures Modernes (http://www.fillm.ulg.ac.be/).

${ }^{28}$ The Council for Scientific and Industrial Research (CSIR) - http://www.csir.co.za/
} 
the "universe-city". That's one thing. But something else is needed in addition: if they go for one language only, they kill research! Now, one international language for scholarship, yes, we need it! Your country has to develop and to promote the knowledge of English, certainly, but also of Spanish. But you need more, and you cannot have two or three languages without translation. And if they treat translation they will do exactly what the Belgians have done with languages. And if you observe a little bit international policy and politics, including in my country, you will see what happens in countries where the question of languages and cultures and translations is not really taken seriously, not even by intellectuals and by universities. So this is really a matter of life and death for scholarship.

ST: Your concern with crucial crossroads in academia leads us to bring up the topic of key moments, or turning points, in our discipline. Therefore, in your view what are the main turning points that occurred in Translation Studies? Have these turning points occasioned indisputable theoretical and conceptual changes that relegated previous theories or approaches to an outdated or inferior status?

LAMBERT: Well, this is, of course, a question like "write another book after Mary SnellHornby's "The Turns of Translation Studies" "29. (laughs) But I am joking. I appreciate the question.

I will try to keep a distance between, say, my individual reply and possible replies on behalf of colleagues who would disagree with me or who would have a very different approach to these kinds of questions. But, still, of course, I have my responsibility and I take it fully. Now, of course, this is like writing another book. So by definition my reply is selective. I do my best for not being eclectic as for me that is something different. So I give a selective answer to these questions, more by examples and on the basis of the selection of important key moments. I do not fully improvise here. I have seen these questions. I have been thinking a little bit about them and I have been writing about this. For instance, one of the articles where I discuss a little bit this kind of questions is the article that I have written for Génesis ${ }^{30}$ - even though it is a journal that is not that well known, I did my best and it is one the articles that I still am very happy to have written recently. Now, of course, its title, "Is Translation Studies too Literary?", is a little bit of an ironical question and I borrow it from a colleague as it was formulated for the first time not by me but by Yves Gambier ${ }^{31}$, who at the moment of its formulation was the president of EST. So because it was used in EST I would say it is an institutional question. He was asking the question whether Translation Studies was too literary, on behalf, say, of people focusing on the question of translation and research on translation, which means that this question was being institutionalized at that moment. Yves Gambier was the successor of Mary Snell-Hornby as the president of EST, which means, again, that these questions are not simply, say, very isolated questions; I think they are more or less symptomatic.

\footnotetext{
${ }^{29}$ Snell-Hornby, Mary. The Turns of Translation Studies: New Paradigms or Shifting Viewpoints? Benjamins Translation Library Vol. 66. Amsterdam/Philadelphia: John Benjamins, 2006. 205 pp. ISBN 9027216746

30 “Is Translation Studies too Literary?”, Génesis. Revista cientifica do ISAI. Tradução e Interpretação, 2005,5 : 20.

${ }^{31}$ http:/ / www.multimodality.it/site/index.php?option=com_content\&task= view\&id=44\&Itemid=81
} 
Now, why is the question of translated literature, or literary approaches to translation, why is it something, like, key? Why is it a privileged entry? Well, I will try not to forget that question when I am supposed to indicate a few turning points in the discipline. I go back to Holmes. James Holmes is supposed to be one of the real fathers of the discipline, although he is not the only one. I know quite a bit of the Historiography of this discipline and very often I fully disagree with, say, the key moments in the discipline and its main turning points, as you call them. That is the case because very often historians, in general, start writing about history long after the object of study has died out. Maybe I am also biased because I did not start writing about this, say, many years later, but I did so from the beginning of the history of the concept of Translation Studies. Now, I do not claim to be, say, the representative of the discipline, but at least I have seen key moments and I have seen, for instance, the interaction between Holmes, Toury and other names, and also where their views were not coinciding at all, whether they were changing, whether there have been conflicts, and so on.

As for the main turning points, I get back to the question of Translation Studies being literary, or too literary. The question by Gambier was asked at the beginning of the century, in 2001 I guess, in Copenhagen. I wrote my article in 2005. I selected it because the question of approaches to translation from the point of view of literature or Literary Studies - those are not the same things - concerned many people involved with research on translation, as it related to the traditional position of Translation Studies at universities. Now, I can shorten my story and make a point, so this is really a thesis. It is very clear that until this very day in universities Translation Studies tends to be located somewhere - sometimes in English Literature, sometimes in Comparative Literature, sometimes in Computer Linguistics, and etc. But the dominant dilemma is still simply, and still nowadays, either Linguistics or Literary Studies. I would say that when we started dealing with translation, for us this was indeed more or less unavoidable. Nowadays, I would say this is a fully outdated dilemma and I think this deserves to be treated as a turning point - I mean, the redefinition of the position of research on translation in the university on the basis of, say, already established disciplines, such as Linguistics and others.

Now, to summarize - and you can really check this in almost all handbooks, all basic books on translation -, almost everywhere you will see that Translation Studies is still either approached - not only Translation Studies, but translation in general - from the point of view of people who are involved in issues of language or people who are involved in the question of literature. But in general the people who deal with literature and who include translation as part of their approach to literature are the people who opened Literary Studies to cultural issues. So this is a little bit of a larger approach. But of course I do not want to reduce Linguistics to more narrow-minded boundaries than it deserves to be done, as Linguistics is a very large field. But it is either Linguistics or Literary Studies. Now, the dilemma and also the question "Is it too literary?", from my point of view, this looks like a rather local debate. So for me, it is an outdated dilemma. And this outdated dilemma has a lot to do with the fact that, of course, Translation Studies, or research on translation, which are also not necessarily the same thing, has been developed and initiated by several groups - after all, in the Middle 
Ages and throughout history the people who were starting to think about translation were very often translators and sometimes philosophers. In fact, literary theory or the theory of language was hardly involved.

One of the striking phenomena until today is the fact that handbooks in Linguistics have hardly a spot for the question of translation. But translation theory, which is not Translation Studies, developed to a large extent in Linguistics, and in a particular kind of Linguistics as it was part of the new kind of Linguistics that was very heavily theoretical and even a little bit structuralist. In fact, there were quite a few translators who also wrote on translation whereas people dealing with the literary phenomena, which were reading and using translations all the time, hardly thought about translation. It is only at the end of the 1960s that this changed a little bit because there were a few people who started approaching translation, say, on a literary background. Now, to what extent they integrated the knowledge that had been collected and gathered and developed in the area of Linguistics, this input was rather limited. Among the first books - and these were already mini-turning points - there were two or three or four German books with a more literary background that integrated a little bit better the linguistic developments. For me, the real key book was the book by the Czech Jiř́ Levý ${ }^{3233}$ because he knew the bibliography in several languages and from several countries - just look at his bibliography, not only the bibliography from Linguistics but even Sociology - and he knew the eastern European developments, from Roman Jakobson ${ }^{34}$ to Juri Lotman ${ }^{35}$, and so many other areas, up to the contemporary Czech structuralists, and so on. This was a turning point because, for the first time, someone was speaking about different disciplines. So there was a struggle between disciplines.

Now, Mary Snell-Hornby, 20 years later, published her very successful book "Translation Studies: An Integrated Approach"36. Why is it a turning point? Because this book is one of the best-sellers in Translation Studies. It was extremely influential! It was one of the first times that references to the tradition of Translation Studies and translation theory were systematically selected not only from Linguistics but also from the more literary background. And there was one common name used: Translation Studies. And here the use of the label developed by Holmes was extremely influential. Now, is Translation Studies too literary? There were several groups that according to Snell-Hornby were representatives of the new approach to translation. One among them was the so called "Manipulation School". This is the name that a few people have used - they have not used it before the mid 1980s - and "Manipulation School" was even used in a book published in 1985 by Theo Hermans ${ }^{3738}$ although Hermans used the word "manipulation" in the title of his book he told me one day that it was a little bit of a kind of a joke. We never used it. In the 1970s, and even in the

${ }^{32}$ http://en.wikipedia.org/wiki/Ji\% $\%$ C5\%99\%C3\%AD_Lev\%C3\%BD

${ }^{33}$ Levý, Jiři (1969). Die Literarische Übersetzung: Theorie einer Kunstgattung". Athenäum, Frankfurt.

${ }^{34}$ http://en.wikipedia.org/wiki/Roman_Jakobson

${ }^{35} \mathrm{http}: / /$ www.ut.ee/SOSE/lotman_eng.html

${ }^{36} \mathrm{http}: / /$ www.benjamins.com/coi-bin/t_bookview.coi? bookid=Z\%2038

${ }^{37}$ http://www.ucl.ac.uk/ ucldthe/index.htm

${ }^{38}$ Hermans, Theo (org). The Manipulation of Literature: Studies in Literary Translation. London and Sydney : Croom Helm, 1985. 
1980s, when discussing Toury and other people, we never used the word "manipulation". So this is a label that has sold well. Now, I do not have too many problems with this concept. But Mary Snell-Hornby talks about the "Manipulation School" and since this book has been influential many people do so on the basis of what Mary Snell-Hornby has written. So this is really a turning point in the formulation of the goals of a new discipline. And the first formulation was, say, somewhere to be located in Göttingen, in Germany, in the Göttingen group, which is and was also a literary group, and Snell-Hornby does not talk too much about that. Now, in that book, the "manipulation" is supposed to be a literary approach to translation.

You asked in one of your previous questions about congresses, papers, and so on, that have been decisive. I remember very well the question I have asked during the "First James S. Holmes Symposium on Translation Studies", in Amsterdam, in 1990 (the proceedings were published in $1991^{39}$ ). The keynote speakers, if I remember well, were first Mary Snell-Hornby and then Lambert. And after Mary Snell-Hornby's paper I have asked her for an answer to one of the very particular paragraphs about the "Manipulation School" in her book entitled "Translation Studies: An Integrated Approach"40. She said that according to Theo Hermans one of the basic principles of what he called "Manipulation School" in his book was that, agreed on the following rule, translation phenomenon cannot be accounted for on the basis of Linguistics only. My question to her in 1990 or 1991 was: "Tell me, Mrs. Snell-Hornby, would you be convinced that the approach to translation can be based on linguistic approaches only?" And her answer was "No!" So I consider this as a turning point. There are so many other ones. There are several moments of that kind. They may not have been recognized in public. Mary Snell-Hornby in the publication of her paper in Amsterdam has never referred to that question, but everyone has noticed her answer. So there is a distance between publications, congresses, and so on. But the dynamics of the discipline is indebted to this.

Now, there are other turning points. So let's leave that kind of soft talk. One of the turning points in the discipline is certainly, first of all, the recognition of the dialogue on behalf of not only Linguistics but the new definition of translation training in relation with research, in particular, for instance, the development of Skopos theory ${ }^{41}$. Skopos theory comes with a background in translation training. Their attempt to link translation training with translation research, and even the attempt to integrate translation history and Historiography, I consider this as a very important decisive moment.

\footnotetext{
39 Kitty M. Van Leuven-Zwart and Ton Naaijkens. Translation Studies: The state of the Art. Proceedings of the First James S Holmes Symposium on Translation Studies. Amsterdam - Atlanta, Ropodi, "Approaches to Translation Studies" 9, 1991, 208 p.

40 Snell-Hornby, Mary (1988/1995). Translation Studies: An Integrated Approach. Amsterdam: Benjamins.

${ }^{41}$ Two relvant references: Schäffner, Christina. "Skopos theory." In Baker, Mona, ed. Routledge Encyclopedia of Translation Studies. London: Routledge, 2001. 235-38. \& Vermeer, Hans J. A Skopos Theory of Translation: Some Arguments For and Against. Heidelberg: Textcontext, 1996.
} 
Another very important and real decisive moment, for instance, is the shift into Corpus Linguistics $^{42}$, say, since the people around Mona Baker ${ }^{43}$ and so many more. Why is this important? We had Mona Baker as a CETRA professor and CETRA obviously is heavily indebted to DTS because it was on the basis of their ideas that we were convinced that you cannot deal with translation without locating your insights on research, and this research, by definition, is linked with culture, and there is no fundamental conflict between culture from the past and culture in our contemporary point of view. Now, what has happened? When Corpus Linguistics has been integrated into research on translation what happened was in fact that the idea of research became linked with the idea of translation theory and theories once and for all as an unavoidable principle. This is not made that explicit. This is more explicit in the case of Toury and DTS, but the other approaches do not contradict this principle; so they take it for granted. Now, in fact, Corpus Linguistics, as I see it, and in its development, is a very important confirmation of the integration of translation research and translation history into the entire discipline. Now, there is something else. It also shows that people who represent these other approaches from, say, previous years, cannot ignore from now on the contribution of Corpus Linguistics as one of the arguments for a systematic approach to translation. These are absolute key moments.

I see another key moment, but this is less clear - and I would even say that our discipline is to be blamed for its late awareness of this problem. In my article in the de Gruyter Encyclopedia $^{44}$ where I have treated the question of translation and globalization I have indicated that the idea of translation and globalization has been accepted, say, with great difficulties, mainly after 2000, hardly before. Now, there is one exception - I know the articles, I know almost the bibliography by heart. Anthony Pym ${ }^{45}$, André Lefevere, myself, we had written a lot on the phenomenon of internationalization - the word "globalization" was not used, but the description and the analysis of these phenomena since the end of the 1980s and during the 1990s is very systematic. Now, in the bibliography of many people who now deal with globalization I see that these people really are not aware of that bibliography - I would say even scholars in Translation Studies sometimes have problems with information, maybe even with amnesia. So why is it so important? Because suddenly it becomes clear that the question of translation cannot be approached only in binary terms, say, on the basis of the dilemma source-target. It is clear that in many cultural environments there are multilateral distributions and kinds of dissemination. Now, many people tend to believe and to assume that this is a phenomenon of the end of the $20^{\text {th }}$ or the beginning of the $21^{\text {st }}$ century. This is absolutely wrong! Otherwise, how can you deal with the history of translation (with the Bible, religious phenomena, legislation)? So it means that the developments and the dynamics of research on translation, little by little, rediscover the past on the basis of new trends in our

\footnotetext{
42 http:/ / en.wikipedia.org/wiki/Corpus_linguistics \& http://www.corpus-linguistics.de/

${ }^{43}$ http://www.monabaker.com/

${ }^{44}$ José Lambert: «Translation and Globalization.» Armin Frank, Norbert Greiner, Theo Hermans, Harald Kittel, Werner Koller, José Lambert, Fritz Paul, Hrsg. Übersetzung - Translation - Traduction. Ein Internationales Handbuch zur Übersetzungsforschung. An International Encyclopedia of Translation Studies. Encyclopédie internationale de la recherche sur la traduction. Berlin \& New York: de Gruyter(Handbücher zur Sprach- und Kommunikationswissenschaft), Bd. II, 2007: 1680-1700.

${ }^{45}$ http:// www.tinet.cat/ apym/
} 
contemporary view on translation. But I would say: is this a problem? I think that most disciplines work and develop in such a way.

ST: As for this rediscovery of the past that you mention it is our perception that the subfield of translation history seems to have gained an upward momentum in recent years. Developments such as the Répertoire mondial des bistoriens de la traduction ${ }^{46}$, under the direction of Jean Delisle ${ }^{47}$, George L. Bastin's ${ }^{48}$ Historia de la Traducción en América Latina", and the International Workshop on "Rethinking Methods in Translation History", which took place at Okan University, Turkey, between $25-27$ September $2009^{50}$, serve as evidence to that. In that Workshop's 'Programme Concept ${ }^{51}$, for instance, many questions were proposed in order to direct the debates. One of those questions called our attention and we would like to have your opinion on it. The question is: "In what ways can translation history be instrumental in furthering understanding of how cultures interrelate with other cultures or with their cultural others?"

LAMBERT: I agree that translation history has gained an upward momentum in recent years. But I would even say that James Holmes already insisted very much on Historiography and its position in the discipline, including also Toury, and so on.

I focus on your question. I was in that conference; it was a good conference, well organized, with good people. I would even say I was a little bit disappointed at the end by the reduction of their goals. So I think, indeed, that there you have a group that might be able to develop a real better methodology of Translation Historiography. My paper was not on translation history but on translation Historiography, and I think they very often simplify that.

Your question: can translation history be instrumental? My answer is, very simply, yes! And I am even working a lot in that area. I am trying to develop several articles on the whole question of universities and their responsibilities in any discipline from the point of view of the history of their own discipline. Say, Mathematics, Medicine, Engineering, if they are not worried about the diachronics in their own discipline, they may notice, one day or another, what the consequences of amnesia may be - for any society, including scholarly societies.

So the function of History and Historiography has always been to function as a scholarlybased model for a better hypothetical approach to the future. This implies that the future is, by definition, different from the past. So then you might say, in simple terms, one is not linked with the other. But from the moment you say even that it is not linked, you have to examine what your basis for comparison is. Now, I was a comparatist in the good old days -

\footnotetext{
${ }^{46}$ http:/ / aix1.uottawa.ca/ jdelisle/fit_index.htm

${ }^{47}$ http://aix1.uottawa.ca/ jdelisle/

${ }^{48}$ http:/ / www.mapageweb.umontreal.ca/basting/

${ }^{49}$ http:/ / www.histal.umontreal.ca/espanol/versionsp.htm

${ }^{50}$ http://www.thw.okan.edu.tr/index.htm

${ }^{51}$ http://www.thw.okan.edu.tr/index_dosyalar/page0001.htm
} 
without comparison we are not very wise... So historical analysis of any tradition may be a better way into the future if people at least know what the rules of the game are. That is why you need concepts!

Now, to what extent can translation and translation history play a role? I try to simplify, but I make it short - so Enseigner c'est simplifier. Mathematics, Philosophy, Medicine, Sociology, any discipline - and we use these disciplines in our universities -, they have been developed somewhere at a given moment; they have a past and they have an intercultural past. There is no discipline that has not been obliged to reformulate in a given language things that have been formulated in different languages. So the very basis of any scholarly work is conditioned by interlinguistic phenomena and translation can never be voided as part of it. So I would say, at least in theoretical-conceptual terms, translation is one of the key problems of university but universities have never accepted this. So "universe-cities" are more "cities" than "universe"! They are local manipulations of would-be universal knowledge. And dealing with that issue should be one of the functions of translation and Translation Studies in universities.

ST: Does the history of translation theory have a role in the production of translation theory? Or are the discourses on translation from the past mere curiosities, or antiques, that dealt with conceptions of translation and language that have little to do with the conceptions and approaches currently established? Have those discourses lost much of their bearing on what can be said about translation?

LAMBERT: I think I have answered the first question implicitly - of course, for wise people and my reply is yes!

As for the second question, I like you formulation here: "mere curiosities, or antiques". I would say, in fact, one cannot avoid thinking of, say, picturesque Historiography, but I know other kinds of Historiography - so this is a particular way of dealing with history. So your formulation is a little bit - and I don `t blame you - a kind of a parody of real Historiography. I mean, this is no real Historiography. That is why in the conference in Turkey I said: "I do not see why you talk about translation history and not about Historiography. When you deal with Historiography you make explicit in conceptual terms what your goals are and the rules".

You have already noticed that I am not someone who tries to exclude too many things. So I have nothing against even bad Historiography. That is what you describe here. I call it bad Historiography, but between brackets. It can be interesting and I know people who are very wise people and who know a lot in this area - and, after all, very often we need them. We should not try to exclude people, we should try to promote people who have explicit goals that go for, say, priorities in our area. So excluding particular approaches to history, Historiography, translation history... Well, I don`t know how well you know Don Quixote and his battles against mills... Why would we worry about that? What we need is to know for what kind of priorities we want to work and what kind of priorities in universities have not been recognized. So, for instance, the history of disciplines, and, say, the Historiography of these disciplines, the history of sciences - I have some contacts with some very interesting people there -, I think this is being underestimated because universities are not 
interdisciplinary enough. Now, translation without interdisciplinarity, I am afraid that this does not make sense in universities. So only interdisciplinary approaches deserve to be really linked with Translation Studies.

Well, for me Translation Studies changed rather basically - and that's one of its turning points again - the very day when $\mathrm{PhD}$ titles and diplomas for Translation Studies were accepted. This is very important because it gives another position to Historiography, to interdisciplinarity, to Sociology, to Political Sciences, to the history of religions, and so on. Now, I have nothing against people who are into, say, a literary approach to translation or a linguistic one because they need to know well their field. But they have no arguments for saying that they represent, simply, Translation Studies. So that the idea of the Linguistic Turn in Translation Studies, and so on, for me this is fully outdated. I have nothing against this attempt but it cannot be the goal of Translation Studies as a discipline.

ST: In this issue of Scientia Traductionis, Alice Leal ${ }^{52}$, a former colleague of ours at UFSC's Postgraduate Translation Studies programme (Pós-Graduação em Estudos da Tradução - PGET) $)^{53}$, and who now holds a teaching position at the University of Vienna, has written an article about her experience in CETRA's Summer School that took place between the $17^{\text {th }}$ and the $28^{\text {th }}$ of August, $2009^{54}$. Leal's account brings to light some criticisms that Martha Cheung ${ }^{55}$, the 2009 CETRA Professor, received from her peers as "she emphasised the importance of 'the local' in the Chinese tradition as a means to find "the other". She continues: "Indeed, this question of whether Translation Studies should be more local as opposed to more global came up throughout the Summer School and the international conference ("The Known Unknowns of Translation Studies"56) that followed, with Andrew Chesterman ranking it amongst the most significant contemporary questions that translation scholars should try to answer." What is your view on this? Incidentally, would it be correct to say that there is a European and North-American hegemony in our discipline? Should we aspire for more diversity?

LAMBERT: I start by the last part of your question because it is the most simple one and then I get to the beginning. As for the question if it would it be correct to say that there is a European and North-American hegemony in our discipline I would say that I know this position and I have even read it on the Internet. For me this question is symbolic. It indicates that the language of the Internet that is used for the interaction, and the observation of the interaction, between Europe and other countries is being used as a key to the question of Translation Studies, which, after all, in my mind, as far as I know the history of this new

\footnotetext{
52 http://ztwweb.trans.univie.ac.at/moodle/user/view.php?id=168\&course $=1$

53 http:/ / www.pget.ufsc.br/

54 http:/ /CETRA.mikt.net/forum/read.php?4,1047

55 http://www.kuleuven.be/cetra/people/Martha_Cheung.html

${ }^{56}$ This event took place at the K.U.Leuven between the $28^{\text {th }}$ and $29^{\text {th }}$ of August of 2009 , and was organized as an international conference in honour of the twentieth anniversary of CETRA and Target (1989-2009). For more information on the event, please check http://www.kuleuven.be/CETRA/anniversary/index.html.
} 
discipline, I simply find it ridiculous! It is simply ridiculous because it means that the channels for communication - which is another matter than the question of research - and the political power, and even the economic power, are used as a solution of scholarly questions. But ok, that is for later. Yet I am upset by this impression. I do not see this as the question of this or that person, but I know it. I remember a similar discussion from Comparative Literature - so I come from Literary Studies, I learned something there - and there it was used in particular to distinguish between Chinese Comparative Literature and western Comparative Literature. The American comparatists, years ago, distinguished between the Americans and the western Europeans. This is all, I would say, political and even partly nationalistic - I call it nationalistic in order not to use a more heavy word. This is simply a nonsensical simplification of research issues.

Now I come to the beginning of the question. Of course, Alice Leal belongs to the 2009 generation of CETRA. There were 20 generations more before her and in those generations the question that Martha Cheung asks was not inexistant but it was not very important. It was a very central question in all the lectures by Martha Cheung. Now, I have even taken part in the discussion - not very fundamentally - and I even intend to write to Martha Cheung because I know what she is puzzled about and this is indeed one of her key questions. This is a very typical question for scholars coming from China and she is formulating these questions well and they are interesting. And it is clear, indeed, that the western world is too much unaware of all the various traditions in other parts of the world.

Now, as for the importance of the local and the question of "the other", I would not call it "the other". I do not know of any research discipline at universities where, I would say, the challenge of the concept of "universe-city" is not central. All universities are in trouble with regard to having information about what is going on elsewhere. I would say that it is symbolic, probably, that people coming from China and in a discipline like Translation Studies - notwithstanding the very rich tradition of discussions about translation in Chinese and Ancient Studies (and I am a little bit involved with it since the 1990s, so since the beginning of CETRA) - have that impression; so this is all very important and very symptomatic. However, it does not mean that this is, I would say, the key problem of Translation Studies; it is one of the many key problems, as in all disciplines.

My main answer is that indeed the question, or the challenge, of university is very much in parallel with what is now called globalization. But globalization is, in fact, a very economic reductionist view on the question of university. My basic discussions of these issues are made clear in the Vol.2 of the de Gruyter encyclopedia, the German encyclopedia, a remarkable encyclopedia, under the item "globalization" 57 . Is globalization an issue for Translation Studies? Of course it is. Hence, I understand very well Martha Cheung`s problems, especially since she is coming from a culture that was not really directly involved in the development of Translation Studies.

${ }^{57}$ Cf. footnote 46. 
Now, what I am sure is that Alice Leal is not referring, for instance, to the movements that have taken place since the 1990s. In 1991, I organized, together with Theo Hermans and other people, in Tokyo, a very successful seminar in Comparative Literature on translation ${ }^{58}$. This has been published, with lots of questions. But since then so much has been achieved in this area, with contributions from Southeast Asia and India. I mean, so much has been done in the international channels, mainly in the Anglophone channels. So I would even say that part of the questions asked by Martha Cheung is still partly conditioned even by, I would say, colonial models. But this is a long story, although it is an interesting issue. The people who work with us in Translation Studies, well, you, of course, have neighbours and neighbours very often happen to live next door and the internet does not solve all the problems.

So it is an important issue, I would not simplify it and I would recommend using that article on globalization where I indicate that, after all, many, many among our colleagues had hardly discovered that concept before the beginning of the $21^{\text {st }}$ century. And in that article I also indicate that before we started CETRA, we already talked about internationalization. But many people in Translation Studies coming from translation training institutes did not read us! Why? Because they were convinced that we were literary people. But we didn't talk about literature: we talked about internationalization and not literature. I organized a session in the Film Congress in Brasilia ${ }^{59}$ - oh, heaven, in Brasilia! - in 1993 or 1994 on the subject of translation and the global village. Nowhere in all the discussions on globalization from recent years has this been mentioned at all! And in the first issue of Target I published an article on translation and the internationalization of communication. Among, say, the prominent translation scholars who refer to this article I see only Anthony Pym. Now, I guess that my colleagues know the review of the journal Target. So they have discovered globalization and internationalization at the beginning of the $21^{\text {st }}$ century. This was not the case, I would say, for us, neither at the origins of Target, nor at the origins of CETRA.

ST: Regarding theoretical hegemony, Leal points out that DTS seemed to be the dominant theoretical framework in display at CETRA's Summer School. In opposition to that, she has called up Hans Vermeer's work as an example of a contribution that should be mentioned in the same breath as Toury's. She has also added that Christiane Nord ${ }^{60}$ was criticised "for the fact that the German functional approach is allegedly solely prescriptive and has not raised any hypotheses", and she added she believes that that is both "irrelevant and unfair". She then reveals Mary Snell-Hornby's thought on the matter, namely that the dominance by DTS, and the lack of interest in the German functional approach, for instance, has a lot to do with the languages in which they were written, namely English and German respectively. How do you see this whole issue?

\footnotetext{
58 The event was the XIIIth Congress of the ICLA (International Comparative Literature Association). Tokyo, 23-28 August 1991.

59 http:/ / www.festbrasilia.com.br/

60 http://www.christiane-nord.de/
} 
LAMBERT: In this case, given that there are very precise different questions, I will try to answer them bit by bit. The questions are interesting and, to tell the truth, I would say I have a lot to say about them.

I would say I disagree! But the feeling and the impression is interesting. And I have an easy point of reference for answering these questions. I would say that lots of things about these questions I would answer them also in relation to Mary Snell-Hornby's book "The Turns of Translation Studies" ${ }^{\prime 1}$. Now, let me try to be more clear.

Of course, the questions are interesting. They are a little bit linked with old traditional discussions about what your approach is, what kind of school you are, etc. So CETRA's summer school is a summer school and it is certainly influenced, in particular, by the concepts in DTS, no doubt about this. But I would disagree fundamentally with this feeling that there is an explicit willingness to reduce, say, research on translation to that approach. Not at all! And it is very simple. As a critical example - it may still be biased or limited - I refer to all the seminars that Dirk Delabastita has given, year after year, for 20 years, on the various approaches to translation. So his panoramic view on the various methodological models and so on is an illustration of the fact that this impression given here by Alice Leal is really narrow. But there is more.

I understand a little bit this feeling. For instance, myself, I have no problem recognizing this: I am a strong advocate, still, of lots of the key tendencies of DTS, which does not mean at all that I would overlook contributions provided, for instance, by Hans Vermeer ${ }^{62}$ (well, of course, they will in general be indicated as Skopos theory, but that is a little bit reductionistic and I would avoid that), and so on. But, first of all, I would say that both Target and CETRA, which are not the same things, have clearly indicated that, say, Hans Vermeer, Christiane Nord, the German functional approach, or whatever you call it, or Skopos theory, are very welcome in our worldview on translation. Hans Vermeer was the second CETRA Professor and Christiane Nord was one of the others. As for Mary Snell-Hornby, I would not treat her as someone who really belongs to the same group, but she is very much in sympathy with it. In her book it is so clear that all the time she tries to show that the German orientation, or what she calls the German functional approach, has also done this and that and that. And even one of the sensitive points is that, all the time, she tries to show that the German functional approach has also some very basic insights in the area of the study of translated literature, which means that there is something like a polemical relationship here. I do not think at all that this polemical relationship is supported, first of all, neither by Target nor by CETRA. And I am very bad at ease with this quote: "She has also added that Christiane Nord was criticised 'for the fact that the German functional approach is allegedly solely prescriptive and has not raised any hypotheses". I would like to know who among the staff members from CETRA would ever have produced such a quotation! I would say that I am bad at ease with this idea because "raising any hypotheses" or "being solely prescriptive" are not relevant

\footnotetext{
61 Snell-Hornby, Mary (2006) The Turns of Translation Studies, Amsterdam \& Philadelphia: John Benjamins \& http://www.benjamins.com/cgi-bin/t_bookview.cgi?bookid=BTL\%2066

62 http:/ / www.fask.uni-mainz.de/Dateien/kelletat-10-02-20-abschied_hjv.pdf
} 
concerns neither for Hans Vermeer nor for Christiane Nord nor for the other representatives of what Mary Snell-Hornby calls the German functional approach. So this is absolutely not fair play. Now, maybe there was a misunderstanding or whatever.

Of course, there are different approaches to the question of translation. And what Alice Leal says is correct at least in one point. I do not see why in the development of Translation Studies and the establishment of a scholarly basis for translation, why Vermeer and the German colleagues should be put aside - there are many other ones such as Frank G. Königs $^{63}$, Paul Kussmaul ${ }^{64}$, Hans G. Hönig ${ }^{65}$, and even the younger generation, certainly the Vienna generation, Franz Pöchhacker, Klaus Kaindl ${ }^{66}$, even from other centers. What is called here the German functional school, well, maybe they happen to make use of German, but I am very bad at ease when in international scholarship they try to link schools with nations and languages. And I am afraid that this is the origin of this misunderstanding. Now, what German group should we refer to here? There are other Germans than these ones - Vermeer himself uses the concept of Skopos theory, no worry about that.

I was the chairman of a debate of a roundtable discussion of very high level in the second year of CETRA with Toury and Vermeer. Now, what turned out to be very clear, indeed, was that their initial and final goals in relation to translation were not really coinciding. What Toury wanted to do from the very beginning was to establish a research discipline. Vermeer was not excluding this but he was working in institutes where they were training translators, whereas we were working in departments of Literary Studies. Now, Christiane Nord, Mary Snell-Hornby, they all come from institutes where the training of translators was more central than research about translation. And the issue is not about interdisciplinarity, because these people are good in interdisciplinarity requirements. But they are more focusing on the perspective of the translator. Now, if one thing is clear even in "The Turns of Translation Studies" by Snell-Hornby is that their focus and the first goal is not really to establish an academic discipline dealing with research on translation and methodology. This is one of the reasons, for instance, why in her book, as one of the achievements of Translation Studies, there is no explicit mention of the new networking and cooperation, for instance, in $\mathrm{PhD}$ levels, the development of academic programs and $\mathrm{PhDs}$ in universities in so many countries, and so on. It is very clear that there is complementarity and that there is no radical opposition here. And I am a little bit upset when this has turned up into a polemical distinction and misunderstanding. So that instead of working on translation so many of my excellent colleagues try to show that Mr. So and So is better than Mrs. So and So, or vice versa, as if this were the real issue. And sometimes this has to do with academic success, and so forth. After all, we are all human beings. This is my real explicit position on this question.

\footnotetext{
${ }^{63}$ http://www.staff.uni-marburg.de/ koenigs/

${ }^{64} \mathrm{http}: / /$ www.Europeansocialsurvey.org/index.php?option $=$ com_content\&task=view\&id=40\&Itemid=217

${ }^{65}$ http://www.uebersetzerportal.de/nachrichten/n-archiv/2004/2004-07/2004-07-09.htm

${ }^{66}$ http:/ / transvienna.univie.ac.at/forschung/forschungspersonal/habilitierte-forscherinnen/kaindl-cv/
} 
ST: Leal mentions that European scholars acknowledge the existence of a poststructuralist (deconstructionist) thought in Translation Studies - advocated by such figures as Haroldo de Campos ${ }^{67}$ and Rosemary Arrojo ${ }^{68}$ - but that they don't feel that much influenced by it - she even points out that the latter's contributions is not always quite well understood by such scholars at their own admission. She adds that "during the conference that followed the Summer School, Anthony Pym spoke about this issue (i.e. the lack of interest in Deconstruction in Europe) as a 'historical conflict' and as a 'main problem' with which 'we' will have to deal at some point". What is your take on it? Is Pym right?

LAMBERT: Well, I happen to have rather explicit positions about this too. As for Pym being right, I would say yes and no. What Pym said, I don't remember very well. I always listen to Pym with great attention, and I know his style very well and it is always interesting to listen to him. But he is not saying exactly the same thing as Alice Leal is saying.

Deconstructionist views are not a monopoly of Haroldo de Campos and Rosemary Arrojo this looks very Brazilian, by the way. I even have indirect views on, say, the reductionist view on research on translation in Brazil as it is displayed in a panoramic and explicit way not only by Alice Leal here but also in Mary Snell-Hornby's book. One of the things I did at the conference in Ouro Preto ${ }^{69}$, and there were some representatives of the deconstructionist view in that conference, I said that notwithstanding the tendency to summarize research on translation in Brazil as being a little bit linked with Haroldo de Campos ' model or with Deconstructionism - in a conference with quite a few people, a large number of people; one that looked more or less like a normal conference on Translation Studies that could take place in Canada or in Western Europe -, although this deconstructionist view has been prominent at a given moment, a little bit fashionable, at the present moment it does not really have such an impact on the actual research going on. Now, when saying so I do not mean at all that this deconstructionist view is not important. I would also add that I know of research done on that basis in France and elsewhere - well, there is Derrida and the whole tradition, so you have it everywhere. And of course, Alice Leal here doesn't say it is Brazilian, but many people have said so, that it is linked with Brazil. Well, I am not that sure about that. I have read a $\mathrm{PhD}$ thesis in my country - well, more than one - on the basis of the Derrida research.

Is the Deconstructionist view important in matters of translation? I am sure that it is an interesting approach. But I remember one of my discussions with Rosemary Arrojo - I know her rather well and I was well in touch with her. After one of her conferences I made a very general remark and asked if, after all, her views that she links with Deconstructionism are that different from basic questions in research and she was very bad at ease.

Now, when Pym says that there is a historical conflict, maybe there is; and that there are contributions coming from that area, maybe there are. I am sure there is an important

\footnotetext{
${ }^{67}$ http://en.wikipedia.org/wiki/Haroldo_de_Campos \& http://www.schulers.com/donaldo/epicof.htm

${ }^{68}$ http://www2.binghamton.edu/comparative-literature/faculty/arrojo-r.html

69 10th Brazilian Translation Forum / 4th International Translation Forum: Along the Paths of Translation. September 7-10, 2009 - Ouro Preto, Brazil.
} 
contribution to be discovered there. But I know of other kinds of approaches about which Anthony Pym has said the same. It is one of his critical roles in the discipline and he is plays it very well. So why not?

I don't try to summarize but I link this again with the tendency to stereotype approaches to Translation Studies. If we have tried to do something in the development of a new discipline, it was exactly the opposite, and I still believe in it. I know weaknesses in our approaches and I am sure that I am, myself, struck with blindness and that I am limiting myself. But we do our best! Our goal was to develop research on translation, not to go for one school or another one. Now, again, as I said, many people try to sell their books well and to be better than their neighbors. I would say I do not think I was really involved in that area.

ST: In a recent issue of Target - Vol. 21, Issue $2^{70}$ - Gideon Toury, co-founder of Target along yourself, published an article called "Incubation, birth and growth: Observations on the first 20 years of Target". In it he offers a series of observations half-baked, he says - about Target's first twenty years. At the opening of his article he states: "I have always been of the opinion that academic periodicals, certainly those that wish to make a difference, should not simply accompany a field of study, documenting its activities (which they certainly do). They should also take part in shaping the evolution of the discipline in question; whether concretely, by putting forward areas, topics and questions for study and discussion, or more abstractly, by instigating a general scholarly atmosphere for others to bask in and possibly absorb." Has Target succeeded in shaping the evolution of the discipline of Translation Studies? If yes, in your view what editorial decisions proved to be key in attaining that goal?

LAMBERT: This quote from Toury's article and your question, this is really very important. And this is very good and critical, but it is not easy to answer. Nevertheless, I do my best. And, of course, I know that I must be, or I must look, very biased because as for the last one who can make such a critical self-evaluation is the person who is in the picture and Toury was more in the picture than I was. So I really consider Toury as the most creative scholar in Translation Studies - I have said so in other circumstances. And I would say that even his sentences here about his view on Target, as you formulated here - well, I have read it in his article but this is well formulated -, it takes it seriously, and it also indicates a very strong critical distance towards his own initiatives.

Now, as has been the case, I simply try to indicate arguments - I am sure that I didn't see everything. But I try to show how and why, probably, Target played an important role in the institutionalization of the discipline. But, of course, not Target only, as there were other initiatives. And I would even say that, for instance, EST was established with the same ambitions - and as it was mentioned before the first president was Mary Snell-Hornby. And in their first publications, even including publications by Daniel Gile, myself and Mary Snell-

${ }^{70}$ http:/ / www.benjamins.com/cgi-bin/t_bookview.cgi?bookid=Target $\% 2021 \% 3 \mathrm{~A} 2$ 
Hornby, one of the reasons why they were looking for $\mathrm{PhD}$ and research training was exactly that. So the EST established in Vienna in 1992 used lots of ideas that were developed a few years earlier in other areas and, after all, this was, I would say, a good coincidence because this indicates how there was something like a common conviction and a common willingness to establish the discipline. So it is as simple as that.

Now, how can we distinguish and indicate, well, which is due to Target or to EST or to CETRA and to other centers and individuals? Well, look in the Bible. There is something written there like "Let's give to Caesar what belongs to Caesar", which is a beautiful opinion but I am not always able to indicate that as well. But I see at least a few features and I know that they were explicit ambitions of Target, and explicit ambitions of Toury. Of course, they have also been influential in our situation in CETRA. I am absolutely sure that we have never worried about the question of what belongs to Caesar or what not... We wanted to develop a discipline! But I was thinking about these questions and among the things in Target that probably reflect, in a very fundamental way, a given view on research on translation it is that there is this willingness to establish a new academic discipline, and to do that on the level of $\mathrm{PhD}$ and post-PhD project-oriented or project-based research.

Now, I give you a few indications and I can tell you that, for instance, in our evaluation of the new contributions, we had a model, we had questions. Among the questions, for instance, there was the absolute requirement in any contribution, and you can check it, that any one of them was based on research ambitions, and that it was looking if the research situation was new or not, if anything had already been established in that area, what was the state of the art, whatever even the languages - but of course our languages are limited, and there, very honestly, we have to recognize that our worldview is limited. But as far as possible we were looking for this very international - I wouldn't say planetarian - challenge. Now, the link with the state of the art, given basic publications - from whatever orientation - that were known and available, that had to be taken into consideration. And if the contributors were not aware of that, except if they were working along a very different model, we accepted also that. So contributions coming from particular paradigms - if we can call them this -, we accepted them if they had their own internal coherence. But in general we obliged the authors to make clear what their assumptions were. This was linked with requirements that are basic requirements for any discipline. We tried to treat approaches to translation in the same way as any scholarly topic in any discipline was treated and we had ideas about this. The same stood for the cultural situation from where the given data were taken, and also for the contextualization of these data and a possibility, even, to have alternative hypotheses, and so forth. Having said that, the institutionalization of the discipline was the absolute priority in the journal.

Another requirement, for instance, was to know also if a given approach applied to very particular data. So very microscopic research was welcomed as well as macroscopic research. But very microscopic research, when it cannot be established as a certain exemplary of paradigmatic value, that should be indicated - how general and how particular are the insights that are established at the end of the article, what is the scholarly contribution, to what extent is a given contribution really a contribution to research and a contribution in a given tradition, 
and not necessarily only in Translation Studies as such. Now, I would say a lot can be said about Translation Studies from this point of view and I am not going to insist much on this so the interdisciplinarity of Translation Studies is one of the critical issues nowadays. Among the other priorities and ambitions of Target when we were evaluating and selecting and planning articles was also, for instance, to what extent was a given contribution a contribution to the dialogue and to the interaction with neighbouring disciplines, and the extension of the field of scholarship, where, for instance, research on language, on social relationships, on media and even on business was involved. So this was additional criteria for positive evaluation.

Another thing, of course, this is very clear, but also this is a very critical point, is the intercultural representativeness of what we were doing. Now, without saying at all that from this point of view we were not supposed to be blamed or not to be under threat, I would say that there was a very systematic effort in that direction. And I would say that even the Chinese, or the Southeast Asian or the Latin American orientation that are developing in a spectacular way nowadays, for us, this was one of the positive things, and we tried to promote it, and it is certainly one of the consequences of the movement developed not only by Target, not only by CETRA, but by so many people, that exactly this new worldview, an enlarged worldview, was taken seriously and had a chance to, say, get through.

Now I have been worried from the beginning with something. When EST was founded, we had no money, CETRA had no money, Target had no money either. So we could not go for, I would say, diplomatic functions and network everywhere around the world. There was no money for that. But everything we could do, we did it. For instance, when we went to Tokyo, and so forth, for Comparative Literature, we were working for Translation Studies also. So with limited resources we tried to do very heavy things also for the internationalization and the international institutionalization of the discipline.

Now, Toury's article is analyzing the contributions from the many countries and it also indicates, say, surprising components of these efforts. I know very well that there are other countries, other cultures and other centers that do the same and that maybe nowadays are more successful. We started it up and I think we opened the gates. Now, it is good that other people continue.

ST: Toury states in his article that in the early 1980s an American or British publisher would probably have responded with the puzzling remark "translation what?" to a proposal of publishing a journal on Translation Studies. He continues: "The fact that this is no longer the case should certainly be attributed, at least in part, to Target's own achievements in putting the discipline on the map." What other journals have also helped put Translation Studies on the map and shape the evolution of our discipline, be they precursors or successors to Target $\left(\right.$ Meta $^{71}, T_{T R}{ }^{72}$ and Babel ${ }^{73}$, mentioned by Toury elsewhere, comes to mind)?

${ }^{71}$ http://www.erudit.org/revue/meta/apropos.html 
LAMBERT: Of course, so simply, like that, I cannot immediately say what is the picture, but there is a picture. First, let me make one point about the origin of Target. Before Target existed we were dreaming about it - I knew all about the project. We have shown our proposal, say, our business plan, to Gerald Prince ${ }^{74}$, a prominent expert in Narratology in the United States, from the University of Pennsylvania, an absolute top guy, and he said: "No doubt, you will get it! You are sure to find a top publisher for this journal." And he was not an expert in Translation Studies but he was an experienced, say, a world level specialist in Narratology.

As for other journals, well, I would distinguish between journals devoted to translation that existed already and new journals. And the fact that I make this distinction already indicates that the idea of establishing a new discipline has been successful - as Toury says, to a large extent this was one of the indications of the impact that Target had on the map for the research on translation. I know lots of journals that existed before, like Meta, and etc. A new journal was TTR, and of course The Translator ${ }^{75}$, the St. Jerome's one. Now, it is clear that the new journals, in the formulation of their goals, have certainly established their positions in relation to the position of Target. Now, of course, they all tried to have something like a profile, that is, a profile of their own. It means that Translation Studies had become a market even for research. So the Translation Studies market exists. And it existed since a given moment. And the traditional journals even adapted their goals. For instance, Meta was a journal that supported very heavily the production of translations, and good translations, and the evaluation of translations. But it opened up its gates to be more research oriented. The fact that translation was not limited anymore to the question "How to produce good translations?" is an illustration of the impact of a new paradigm.

Now, when Alice Leal, for instance, says that DTS is too dominating at CETRA, not like the ideas of Vermeer or of the proponents of the German functional approach, there is at least one difference: the goals, neither of Vermeer nor of Nord nor of Snell-Hornby, who have always been CETRA professors ${ }^{76}$, their goals were not, first of all, to establish the academic discipline. And the establishment of the PhD programs and research on translation is the achievement not of one person nor another person nor one journal, and so forth: it is the result of collective efforts. But these collective efforts are nearer the goals of DTS, as we see it, than the goals of, say, the Skopos theory. And I do not blame anyone at all. I would say that in the Skopos theory and in the German school there have been excellent PhDs and I know excellent and successful scholars who would now speak, indeed, about the establishment of the discipline, and they will not try to say that this is due to this person or to that person. It means that there is a new view, a collective assumption of what the tasks and responsibilities in this area are. Making PhDs on translation that were not linked with, say, the pragmatics of the translation task and the training of translators, this idea, before the 1990s, I

\footnotetext{
72 http://www.erudit.org/revue/ttr/apropos.html \& http://www.uottawa.ca/associations/actcats/English/Journal_TTR/Journal_TTR.htm

73 http://www.benjamins.com/cgi-bin/t_seriesview.cgi?series=babel

74 http://ccat.sas.upenn.edu/roml/french/people/prince.html

75 http://www.stjerome.co.uk/periodicals/journal.php?j=72

${ }^{76}$ http://www.kuleuven.be/cetra/professors/cetraprofessors.html
} 
would like to see, so people can demonstrate to me, where it has been expressed. So this is new in the academic world and I would say that the progressive deletion of the borderline between translation training institutes and universities, which was one of the features since World War II, this has disappeared, and this has partly disappeared because there is a common ground now in the area of PhD on Translation Studies - I would say I know from which area in Translation Studies this comes and from which area it does not really come. So, I would say, is this coming from Target? It is certainly not only Target and CETRA, but the common efforts and the parallel orientations, and also the fact that so many people who also came, for instance, from the German field... Apropos, so far we did not mention at all - and in your documents they are not mentioned at all - this very impressive and remarkable center in Göttingen, with their dozens of heavy books and their dozens of $\mathrm{PhDs}^{77}$. Well, they really have accepted the idea of research. And they would not say: "Well, we work along Toury" They even didn't like his proposals too much, but they did exactly the research that he was promoting - with different rules - and they went for PhDs degrees. And I have been myself supervisor of one of the $\mathrm{PhDs}$ coming from Göttingen with a colleague member in the $\mathrm{PhD}$ committee coming from Göttingen to Leuven. So we worked together. So these are achievements that in many panoramic states of the art very often are forgotten, but Göttingen has been extremely important.

Now, there are more than journals. By the way, I should add that there are very important book series. And in these book series one of the important contributions comes from the new PhDs degrees. So this promotional movement in the book market is heavily supported by PhDs. Even yesterday on the Internet I discovered a $\mathrm{PhD}$ from Massachusetts, from Amherst ${ }^{78}$, whose advisor was Edwin Gentzler ${ }^{79}$. He was one of our alumni in the year that Susan Bassnett was teaching and I do not see that he is simply applying principles from DTS; he even tries to show that he is a little bit in disagreement, and very often he tries to show even that he is in agreement with me but not really with Toury nor with DTS, and so on. So this is all looking for your position. But I don't think that this is really the point. It indicates that something has been achieved in common and in interaction. So the impact of the things that I have been discussing, this impact is very obvious, I would say, on almost every place.

ST: As for the decision to have English as the main, or almost sole, language of publication, Toury says that "this dictate had important implications for Target, especially in view of the fact that it has translation as its subject-matter." He also states that "the restriction on the use of languages has no doubt exerted a considerable impact on the growing marginalization in Target of research carried out in certain parts of the world, using languages such as Italian or Portuguese, even German, not to mention Chinese and Japanese. As is well known, and despite some changes that have taken place of late, many scholars still prefer to write and publish in

\footnotetext{
${ }^{77}$ Professor Emeritus Armin Paul Frank of Georg-August-Universität Göttingen is a standout representative of the Göttingen group and his books on the subject of translation are important representatives of the production of that group. More info: http://www.amstud.uni-goettingen.de/personal.php?mit_id=89\&bereich=personal

78 http://www.umass.edu/complit/programs_phd.shtml

79 http://www.umass.edu/complit/people_fac.shtml\#gentzler
} 
world languages other than English, not to mention their own parlance. One place where this state of affairs has been undergoing some change is Spain, where English has become more and more a language of scientific communication." These various statements inspire a series of questions whose general topic you have already dealt with, in broader terms, on this interview; let us narrow its focus a little bit as to how it relates to publications. 1) How does this monolingual approach to publishing cope with the fact that the subject-matter in question, translation, presupposes the interplay of at least two languages? 2) Considering Toury's own admission of the problem of marginalization of research due to language policies that do not privilege diversity, which tools can be used to allow linguistically-variegated contributions to the field to gain more visibility? 3) On the flipside, what are the advantages of having a lingua franca as the linguistic vehicle for "inter-academic communications"?

LAMBERT: So it is a long question. It is an interesting and complicated question and I am sure that you remember well that last year (2009) in Florianópolis I was heavily insisting on that. As for Toury's position about this question of languages, I would say it is for the first time that I see, myself, this very explicit positioning on his behalf. We hardly discussed it in the history of Target and I would say I blame myself and I would blame the Target team for this. But his views are interesting and in general I would support them, but I would go further. After all, your questions go into that direction too.

Now, I would say that I am one of the advocates of a change of the language policy in research on translation. Maybe we could not even afford talking about it at the beginning, because you depend on publishing houses, you depend on publication channels, you need to get recognized in the market situation, and so on. It is due to the fact that, little by little, Translation Studies and certain areas of publications have been institutionalized that you can try to move and redefine the borderlines. But it is also because the issue of English as an academic language is now much more of a hot topic, and I hope it will still become hotter than it is now - it deserves to be so. I would say that the reduction of the language of publication to mainly English - English as a dominant language - is one of the weaknesses of our discipline and it is also a little bit counterproductive. And you can see it reflected in many publications. Even our top colleagues very often are themselves simplifying because they do not look into other languages than English anymore. I published in French in the beginning and more and more I moved into English because I realized that people did not even look at the articles in French since they were not very good at it. Now, Gideon Toury, to be frank, is not the most polyglot scholar in translation, but he knows a few languages. He is very much aware of it. I know many among his countrymen who are much better in the internationalization of languages. And one of the reasons, I would say, why he tried to work with us was that at least we had access not only to French but also to the Latin languages. But of course this is only a small part of this globe and we need much more.

Now, I would even say that this issue that you have brought up here and your questions at the end are particularly interesting and important because you write them from Brazil. And I would apply most of these questions to the academic policy of your country. I would say that you absolutely need, first of all, a better mastery, an active mastery, of the dominant 
international language, which is English (even in my country, very often the people from the positive sciences say "everything in English", but they need some specialists in English in order to brush up their own articles).

I have written a lot about this and I am going to take part in an important conference in Europe, in Lisbon, a conference on Social Psychology, Organization Theory, Management Research, , and so on ${ }^{80}$. It is about multilingualism that we talk there and the role played by translation in multilingualism, something you have in everyday language. But the question of academic communication is a very particular and privileged area, and this is still very different from the question of translation in general. But to show that this is absolutely crucial and that the academic world is on the borderline of business, I would say, look at the Internet and the impact that the internet has on our world of publication and research.

ST: Finally, Target is available electronically on Ingentaconnect. However, its online availability is restricted to its most recent 20 issues. How about doing some "journal archeology" and making the earlier issues of Target available electronically as well?

LAMBERT: This is a good question, it makes perfect sense and it will be communicated to my colleagues, so we will work on that. So by definition the answer can only be yes!

José Lambert

Jose.Lambert@arts.kuleuven.be

The interview was conducted by Gustavo Althoff \& Lilian Fleuri

Universidade Federal de Santa Catarina

gualthoff@gmail.com \& lilianfleurigmail.com

\footnotetext{
${ }^{80}$ 26th EGOS Colloquium, Lisbon, 2010. Waves of Globalization: Repetition and difference in organizing over time and space. July $1-3,2010$
} 